\title{
Species-specific phytoplankton growth rates via diel DNA synthesis cycles. I. Concept of the method
}

\author{
Edward J. Carpenter, Jeng Chang
}

Marine Sciences Research Center, State University of New York, Stony Brook, New York 11794, USA

\begin{abstract}
A conceptual basis is established to estimate the duration of cell cycle phases from a partially synchronized population. This information, together with the time course of cell cycle phase fractions, can be applied to estimate species-specific, in situ growth rates of phytoplankton. The model adopts the paired-nuclei method of McDuff \& Chisholm (1982) with the substitution of the sum of $S, G 2$, and $M$ phases of the cell cycle as the terminal event. Quantitative fluorescence microscopy is used to measure unicellular DNA contents through a diel cycle. The model has the advantage of avoiding bottle incubations and allows the measurement of species-specific growth rates.
\end{abstract}

\section{INTRODUCTION}

The measurement of phytoplankton species-specific growth rates is important in the field of biological oceanography for several reasons. Growth rate information is necessary to determine the significance of a species in the food web and also to understand environmental factors which affect its physiology. Obviously, in understanding food chains, it is necessary to know how rapidly certain species are dividing; species differ in their chemical composition, food value and size, as well as in physiological capabilities such as $\mathrm{N}_{2}$ fixation or toxin production. Ideally, a method for measuring species-specific growth rates should avoid bottle incubations, since there is abundant evidence that problems can exist during incubation (Venrick et al. 1977, Carpenter \& Lively 1980, Peterson 1980).

There have been a number of attempts to measure growth rates of individual species. Several investigators have used autoradiography to measure carbonspecific phytoplankton growth (Knoechel \& Kalff 1976 , Descolas-Gros 1980, Douglas 1984). Phytoplankton 'cages' have been employed by Owens et al. (1977). and their use has been reviewed by Sakshaug \& Jensen (1978). A recent innovative method developed by Rivkin \& Seliger (1981) relies on micropipetting single cells from bottle incubations into scintillation vials where their activities can be individually measured.
However, all of these methods are relatively tedious and require incubations to label phytoplankton.

The application of the eukaryotic cell cycle concept provides a way to measure the species-specific, in situ, growth rate of phytoplankton without incubation if some knowledge about a terminal event is obtained experimentally. A terminal event, by definition, is the stage which may start from any point on a cell cycle but it must last until cytokinesis (Mitchinson 1971). Since mitosis is a terminal event in the cell cycle, the pairednuclei method proposed by McDuff \& Chisholm (1982) can be used to calculate the population growth rate according to the following equation:

$$
\mu=\frac{1}{n T_{d}} \sum_{i=1}^{n} \ln \left(1+f_{1}\right)
$$

where $\mu=$ daily mean specific growth rate $\left(\mathrm{d}^{-1}\right) ; T_{d}=$ duration of mitosis; $f_{u}=$ fraction of cells undergoing mitosis in the $i^{\text {th }}$ sample; $n=$ number of samples in a $24 \mathrm{~h}$ measuring cycle. (For convenience, all symbols are listed in Table 1.)

This method has been employed by Swift et al. (1976) for measuring the in situ growth rates of the dinoflagellates Pyrocystis fusiformis and $P$. noctiluca, and Weiler \& Chisholm (1976), Weiler \& Eppley (1979) and Coats \& Heinbokel (1982) for other species. One disadvantage of this technique is that the interval of cell division, the terminal event in the equation, can be relatively short, and the microscopic observation of cytokinesis can be 
Table 1. Symbols used in the text

\begin{tabular}{|c|c|}
\hline $\begin{array}{l}f_{S}, f_{G 2 M} \\
g 1, g 2\end{array}$ & $\begin{array}{l}S, \text { and } G 2 M \text { phase fraction } \\
\text { Numer of compartments in } G 1 \text {, and } G 2 \\
\text { phases }\end{array}$ \\
\hline$h$ & Location of the mode of cell cohort at $t=t_{2}$ \\
\hline$j$ & Location of the mode of cell cohort at $t=t_{1}$ \\
\hline k & Last compartment in the cell cycle \\
\hline$m$ & Number of compartments in $M$ phase \\
\hline$N$ & Total number of cells in the population \\
\hline$n$ & Number of samples taken in a 24 h cycle \\
\hline$n_{i}$ & Number of cells in Compartment $i$ \\
\hline$n_{S}, n_{G 2 M}$ & Number of cells in $S$, and $G 2+M$ phases \\
\hline$r$ & Instantaneous growth rate \\
\hline$\hat{r}$ & Estimator of $r$ \\
\hline$s$ & Number of compartments in $S$ phase \\
\hline$T_{S}, T_{G 2 M}, T_{d}, T_{X}$ & $\begin{array}{l}\text { Duration of } S, G 2+M \text { phases, mitosis, } \\
\text { and the terminal event } X\end{array}$ \\
\hline$t$ & Time \\
\hline$t_{1}, t_{2}$ & Time when $n_{s}$ and $n_{G 2 M}$ reach maximum \\
\hline$v$ & Traveling speed of a cell in the cell cycle \\
\hline$\alpha$ & Time difference between $t_{1}$ and $t_{2}$ \\
\hline$\beta$ & Ratio between $T_{S}$ and $T_{G 2 M}$ \\
\hline$\mu$ & Daily mean growth rate \\
\hline$\mu_{G 2 M}, \mu_{S+G 2 M}$ & $\begin{array}{l}\mu \text { estimated with } G 2+M \text {, and } S+G 2+M \\
\text { as the terminal event }\end{array}$ \\
\hline$\Phi$ & Release factor of Compartment 0 \\
\hline
\end{tabular}

subjective. An improvement on this method can be the substitution of a longer lasting terminal event which can be measured quantitatively. For example, the substitution of the $G 2+M$ phase of the diel cycle of DNA synthesis can improve on the estimation of growth rate in that it lasts longer than cytokinesis. Secondly, this event can, with the aid of DNA-specific fluorochromes, be accurately measured using a quantitative epifluorescence microscope system or a flow cytometer.

An important but hard to measure variable in the equation is the duration of mitosis. For some species, $T_{d}$ can be estimated visually by monitoring the time required for a cohort of cells to migrate from the double nucleated stage to a second stage such as completion of cytokinesis. However for other species, it is difficult to discern both start and stop points for a terminal event. Thus laboratory measured $T_{d}$ values are usually used. The validity of this latter approach has been questioned since the duration of $T_{d}$ or other terminal events may change with environmental conditions, especially temperature (Olson et al. 1986, Rubin 1981). In this study we have tried to build a functional model of the cell cycle which allows the in situ estimation of the duration of terminal events. The terminal event with the longest duration will then be used in growth rate estimation.

\section{DESCRIPTION OF THE MODEL}

The cell cycle clock concept of Edmunds \& Adams (1981) is used as a biological basis for our model. It is assumed that each algal cell has 2 internal timers (Fig. 1). The cytochron timer is non-cyclic and can be reinitiated at some point in the external light-dark cycle. The cytochron keeps the timing of cell-divisioncycle events such as the time to start the $S$ phase. After the cytochron sends out the signal for cytokinesis, it ceases functioning, and the cell remains in an untimed period after the stop point until it is picked up by the subsequent cytochron at the next start point. A second timer, the circadian clock, which is entrainable by external light-dark cycles, can couple to the cytochron and maintain the ryhthm of the cytochron even after the external light-dark cycle has been removed. It is this circadian clock which can 'insert' time segments to the cell cycle. As a result, cells which cannot perform mitosis for every light-dark cycle due to unfavorable growth conditions are forced to extend their generation time to 2 or more light-dark cycles.



Fig. 1 Cell cycle models discussed. Top panel illustrates the 5 phases of the cell division cycle. Center the cytochron and circadian timers were proposed and attached to the cell division cycle by Edmunds \& Adams (1981) to interpret how a cell cycle can be entrained by an external light-dark cycle. Bottom panel shows the basic structure of the TakahashiKendall model (Takahashi 1966). A small $\Phi(t)$ will increase the resident time of cells in Compartment 0 so it is analogous to a longer time segment inserted by the circadian timer 
This concept of the cell cycle can be conveniently transformed to mathematical expressions by using a special case in the Takahashi-Kendall model of cell cycle kinetics (Takahashi 1966, 1968, Eisen 1979). Assumptions of this model are as follows:

(1) The cell division cycle is divided into $(k+1)$ hypothetical compartments, numbered from 0 to $k$. A cell which has just passed the start point of the cytochron will be placed in Compartment $1 \mathrm{~A}$ cell in the last stage of mitosis is in the $k^{\text {th }}$ compartment (Fig. 1).

(2) We assign $g 1, s, g 2$, and $m$ compartments to $G 1$, $S, G 2$, and $M$ phases respectively so that $G 1$ occupies Compartment 1 to Compartment $g 1$; $S$ accupies Compartment $(g 1+1)$ to $(g 1+s)$; and so on. Under a particular set of environmental conditions, $g 1, s, g 2$, and $m$ are constants, and they form the deterministic part of the cell cycle (Smith \& Martin 1973). However, $g 1, s, g 2$, and $m$ may change when the cell is under different growth conditions (Olson et al. 1986).

(3) Compartment 0 is assigned to the G0 phase corresponding to the untimed period in Edmunds \& Adam's (1981) model

(4) Once a cell enters Compartment 1, the cytochron will make this cell travel from Compartment 1 to $k$ at a constant rate $v$.

(5) The transfer of cells from Compartment 0 to 1 , however, is controlled by a release factor $\Phi(t)$. Here $\Phi(t)$ may be regarded as the combination of the circadian clock and the starting point of the cytochron (Fig. 1). The oscillation of $\Phi(t)$ with the external lightdark cycle generates one or more cohorts of cells each day and sends them down the cell division cycle from Compartment 1 to $k$. The total cells transferred from Compartment 0 to 1 by $\Phi(t)$ determines the population growth rate of the present cycle.

(6) No cell death.

(7) After cells leave Compartment $k$, they divide to 2 daughter cells and rejoin Compartment 0 .

Let $n_{i}(t)$ be the number of cells in the $i^{\text {th }}$ compartment at time $t$. According to the Takahashi-Kendall equations (Eisen 1979), we obtain

$$
\begin{aligned}
\frac{\mathrm{d} n_{i}}{\mathrm{~d} t} & =v\left(n_{1-1}-n_{i}\right) \quad i=2,3, \ldots, k \\
\frac{\mathrm{d} n_{0}}{\mathrm{~d} t} & =2 v n_{k}-\Phi n_{\circ} \\
\frac{\mathrm{d} n_{1}}{\mathrm{~d} t} & =\Phi n_{\circ}-v n_{1}
\end{aligned}
$$

Also, from Assumptions 2 and $4, T_{S}$ and $T_{G 2 M}$, which are the durations of the $S$ and $G 2+M$ phases respectively, are defined as

$$
\begin{aligned}
& T_{S}=s / v \\
& T_{G 2 M}=(g 2+m) / v
\end{aligned}
$$

\section{ESTIMATING GROWTH RATE BY A TERMINAL EVENT}

If the fraction of the cell population in an identifiable terminal event is known, the same procedure as used by McDuff \& Chisholm (1982) to derive the mean growth rate between time $t$ and $t+T_{d}\left(\bar{\mu}_{t, t+T_{d}}\right)$ can also be applied to this Takahashi-Kendall model. The mean growth rate $[\hat{r}\{t\}]$ over the period from the time $\left(t-1 / 2 T_{X}\right)$ to $\left(t+1 / 2 T_{X}\right)$ may be expressed as:

$$
\hat{r}(t)=\frac{1}{T_{X}} \ln \left[1+f_{X}\left(t-1 / 2 T_{X}\right)\right]
$$

where $T_{X}=$ duration of the terminal event $X$. Averaging $\hat{I}(t)$ over a $24 \mathrm{~h}$ period will give the daily mean growth rate $(\mu)$ in Eq. (1) with $T_{d}$ replaced by the more general $T_{X}$.

\section{DETERMINATION OF THE DURATION OF $S$ AND $G 2+M$ PHASES}

A graphic method is used to estimate $1 / 2\left(T_{S}+T_{G 2 M}\right)$. Little is known about the general shape of cell cohorts released by $\Phi(t)$. According to our model, if a fixed compartment is selected between Compartment 1 and $k$, and the cell number in this compartment is monitored over a period of time, the time sequence of cell numbers should reflect the shape of the cell cohort when the cohort is passing through the selected compartment. In various phased populations, many studies have monitored frequencies of mitotic cells, which can be regarded as using mitosis as the selected compartment (Weiler \& Chisholm 1976, Rubin 1981, Braunwarth \& Sommer 1985). Cell fractions observed at the starting and end points of the $S$ phase of a synchronous mammalian cell culture were also studied by Zietz (1980). All results showed that cell cohorts revealed by the time sequences of cell fractions at selected compartments have a good symmetry about their mode although most of them were skewed a little to the left. Since fractions are cell numbers normalized by the population size, considering the population size increases with time, these slightly skewed fraction curves imply symmetrical cell cohorts when the absolute cell numbers are used to present data. Therefore, we assume that each cohort of cells generated by $\Phi(t)$ is bell-shaped, that is, the cohort has a single maximum and is symmetrical about its mode (Fig. 2). At time $t$, if the mode of this cohort sits in Compartment $j$, the following relationship can be observed:

$$
n_{j-a}(t)=n_{j+a}(t)
$$

where $a=a$ constant; and satisfies $(j-a) \geq 1$ and $(j+a) \leq k$. The total number of cells in the $S$ phase $\left(n_{S}\right)$ is the sum of $n_{g 1+1}, n_{g 1+2}, \ldots$, and $n_{g 1+5}$, hence, 

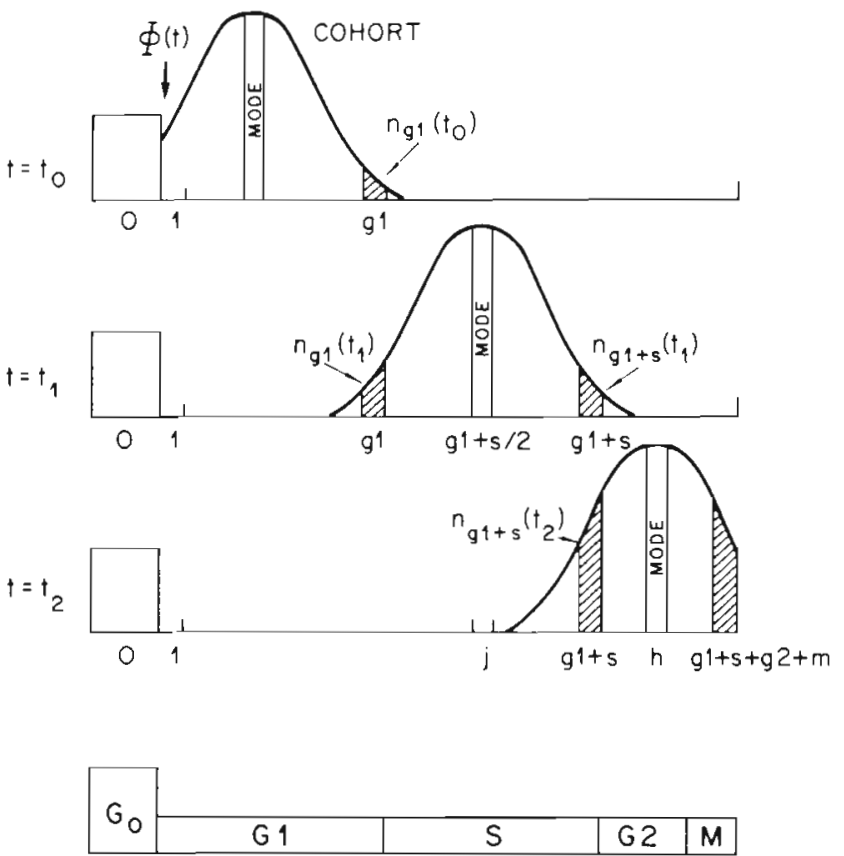

Fig. 2. Positions of the cell cohort generated by $\Phi(t)$ at 3 different time points: $t_{0}, t_{1}$, and $t_{2}$. Area under the curve in each compartment represents the number of cells in that compartment at the given time

$$
n_{S}(t)=\sum_{i=g 1+1}^{g 1+s} n_{i}(t)
$$

According to Eq. (2),

$$
\begin{aligned}
& \frac{\mathrm{d} n_{S}}{\mathrm{~d} t}=\sum_{i=g 1+1}^{g 1+s}\left[\frac{\mathrm{d} n_{i}}{\mathrm{~d} t}\right] \\
& =v\left(n_{g 1}-n_{g 1+1}+n_{g 1+1}-n_{g 1+2}+\ldots .\right. \\
& =v\left(n_{g 1}-n_{g 1+s}\right) \\
& \left.+n_{g 1+s-1}-n_{g 1+s}\right)
\end{aligned}
$$

The number of $S$ cells of the population, $n_{S}(t)$, can be plotted as a function of time. If we observe a maximum of $n_{S}(t)$ at time $t_{1}$, that is,

$$
\left(\frac{\mathrm{d} n_{S}}{\mathrm{~d} t}\right)_{t_{1}}=0
$$

the following relation can be deduced from Eq. (7):

$$
n_{g 1}\left(t_{1}\right)=n_{g 1+s}\left(t_{1}\right)
$$

Comparing Eq. (9) with Eq. (5) indicates that the mode of cohort (Fig. 2) locates in Compartment $j$ and

$$
\begin{aligned}
& g 1=j-a_{i} \quad g 1+s=j+a \\
& \text { or } \quad j=g 1+1 / 2 s
\end{aligned}
$$

Similarly, if we observe a maximum of $n_{G 2 M}$ at time $t_{2}$, the mode of the same cohort must have moved to Compartment $h$ (Fig. 2) where

$$
h=g 1+s+1 / 2(g 2+m)
$$

The time required for the mode moving from Compartment $j$ to $h$ is

$$
(h-j) / v=1 / 2[s / v+(g 2+m) / v]=\left(t_{2}-t_{1}\right)
$$

According to Eq. (3), we rewrite Eq. (12) as

$$
\left(t_{2}-t_{1}\right)=1 / 2\left(T_{S}+T_{G 2 M}\right)
$$

However, the curves obtained experimentally are not $n_{S}(t)$ and $n_{G 2 M}(t)$. Rather, they are fractions of $S$ and $G 2+M$ cells of the population as a function of time defined as:

$$
f_{S}(t)=\frac{n_{S}(t)}{N(t)} ; \quad f_{G 2 M}(t)=\frac{n_{G 2 M}(t)}{N(t)}
$$

where

$$
N(t)=\sum_{i=0}^{k} n_{j}(t)
$$

Differentiating $f_{S}(t)$ with respect to time gives

$$
\begin{aligned}
\frac{\mathrm{d} f_{S}}{\mathrm{~d} t} & =\frac{1}{N(t)}\left[\frac{\mathrm{d} n_{S}}{\mathrm{~d} t}-\frac{\mathrm{d} N(t)}{\mathrm{d} t} \frac{n_{S}(t)}{N(t)}\right] \\
& =\frac{1}{N(t)} \frac{\mathrm{d} n_{S}}{\mathrm{~d} t}-r(t) f_{S}(t)
\end{aligned}
$$

where $r(t)$ is the instantaneous growth rate. At $t=t_{1}$,

$$
\left(\frac{\mathrm{d} f_{S}}{\mathrm{~d} t}\right)_{t_{1}}=\left(\frac{\mathrm{d} n_{S}}{\mathrm{~d} t}\right)_{t_{1}}=0
$$

if, and only if, $r\left(t_{1}\right)=0$. As an approximation, we can assume that $r\left(t_{1}\right)=r\left(t_{2}\right)=0$ so the time difference between the 2 successive maxima on $f_{S}(t)$ and $f_{G 2 M}(t)$ is still $\left(t_{2}-t_{1}\right)$ as in Eq. (13). This quantity multiplied by 2 should be a good estimator of $\left(T_{S}+T_{G 2 M}\right)$.

\section{INCREASING THE ACCURACY BY ITERATION}

If the experimental result shows that our assumption $r\left(t_{1}\right)=r\left(t_{2}\right)=0$ will introduce severe bias in the growth rate estimation, a more complex but accurate way can be used to increase the accuracy. As suggested by Eq. (16), the time difference between the $n_{S}(t)$ and the $f_{S}(t)$ maximum is obtainable provided that the instantaneous growth rate, $r(t)$, is known. The best estimator of $r(t)$ we can have is the $\hat{r}(t)$ defined by Eq. (4). Since $\hat{r}(t)$ is some kind of averaged $r(t)$ over the span of the chosen terminal event, a shorter terminal event should generate an $\hat{r}(t)$ closer to $r(t)$. In this model, the shortest terminal event is the $G 2+M$ phase so we must determine its duration. Now, if we know the ratio of $T_{S}$ ' $T_{G 2 M}$, we can solve for $T_{S}$ and $T_{G 2 M}$ in Eq. (13) readily. Since we can distinguish $S$ and $G 2+M$ cells experimentally, 2 terminal events may be used to calculate the population growth rate $\mu$. Using Eq. (1), 


$$
\begin{gathered}
\mu_{G 2 M}=\frac{1}{\left(T_{G 2 M}\right) n} \sum_{j=1}^{n} \ln \left[1+f_{G 2 M}\left(t_{j}\right)\right] \\
\mu_{S+G 2 M}=\frac{1}{\left(T_{S}+T_{G 2 M}\right) n} \sum_{j=1}^{n} \ln \left[1+f_{S}\left(t_{j}\right)+f_{G 2 M}\left(t_{j}\right)\right]
\end{gathered}
$$

Note that $\mu_{G 2 M}$ and $\mu_{S+G 2 M}$ is the growth rate of the same population, hence,

$$
\mu_{G 2 M}=\mu_{S+G 2 M}
$$

Consequently,

$$
\frac{T_{S}}{T_{G 2 M}}=\frac{\sum \ln \left[1+f_{S}\left(t_{j}\right)+f_{G 2 M}\left(t_{j}\right)\right]}{\sum \ln \left[1+f_{G 2 M}\left(t_{j}\right)\right]}-1
$$

Let

$$
\begin{aligned}
& \alpha=t_{2}-t_{1} \\
& \beta=\frac{\sum \ln \left[1+f_{S}\left(t_{j}\right)+f_{G 2 M}\left(t_{j}\right)\right]}{\sum \ln \left[1+f_{G 2 M}\left(t_{j}\right)\right]}-1
\end{aligned}
$$

From Eq. (13) and (21)

$$
\begin{aligned}
& T_{S}=2 \alpha \beta /(\beta+1) \\
& T_{G 2 M}=2 \alpha /(\beta+1)
\end{aligned}
$$

Next, after $T_{S}$ and $T_{G 2 M}$ are obtained by assuming $r\left(t_{1}\right)=r\left(t_{2}\right)=0, r\left(t_{1}\right), r\left(t_{2}\right)$ can actually be estimated by $\hat{r}\left(t_{1}\right)$ and $\hat{r}\left(t_{2}\right)$ from Eq. (4). With Eq. (8) in mind, substituting $\hat{I}\left(t_{1}\right)$ back in Eq. (16) for $r(t)$ yields

$$
\left(\frac{\mathrm{d} f_{S}}{\mathrm{~d} t}\right)_{t_{1}}=-\hat{r}\left(t_{1}\right) f_{S}\left(t_{1}\right) \neq 0
$$

Graphically, we can find a new $t_{1}$, call it $t_{1}{ }^{\circ}$, at which the $f_{S}(t)$ curve has a slope of $-\hat{r}\left(t_{1}\right) f_{S}\left(t_{1}\right)$. Similarly, a new $t_{2}{ }^{\circ}$ can be found for the $f_{G 2 M}(t)$ curve. The quantity $\left(t_{2}{ }^{*}-t_{1}{ }^{*}\right)$ thus gives a better estimation of $1 / 2$ $\left(T_{S}+T_{G 2 M}\right)$ and the new set of $T_{S}{ }^{*}$ and $T_{G 2 M^{*}}$ can be calculated from Eq. (23).

$T_{S}{ }^{*}$ and $T_{G 2 M}{ }^{*}$ can generate a more accurate $\mu$ and $\hat{r}$. This better $\hat{r}$ can be fed back to Eq. (24) again to locate a second more accurate position of the mode of the cell cohort which is theoretically at $\left(g^{1}+1 / 2 s\right)$. This iterative method can be repeated many times until satisfactory $T_{S}$ and $T_{G 2 M}$ values appear. Mathematically, it is difficult to show that the iteration converges to the actual $t_{1}$ and $t_{2}$. However, according to our experiences with a computer simulation so far, the iterative method fails only when $I(t)$ becomes unreasonably high, and the magnitude of the slope obtained from the right hand side of Eq. (24) becomes so large that there exists no point with the corresponding slope on $f_{S}(t)$ and $f_{G 2 M}(t)$ curves.

\section{DISCUSSION}

A clock-controlled rhythm is used as the conceptual basis to derive our calculation procedures for phase durations and growth rate. However, another gener- ally accepted hypothesis regards phased cell division as a result of a forced oscillation of the cell cycle (Spudish \& Sager 1980). According to this mechanism, cell populations are synchronized by the external light-dark cycle solely because a segment of the cell cycle is light dependent. Since the forced oscillation mechanism also forms one or more cell cohorts along the cell cycle in a phased population (Chisholm et al. 1984, Vaulot \& Chisholm 1987), calculation procedures proposed here should be still valid in predicting phase durations and growth rates. If the forced oscillation is used as the conceptual basis, the Compartment 0 could be used to simulate the light-dependent segment in $G 1$ phase, and the cell cohorts generated by $\Phi(t)$ will be composed of cells which have seen enough light already.

The application of our technique is dependent on the assumption that phytoplankton divide in phase in their natural habitat. If division is random throughout the day then the phase durations are impossible to estimate. However, there is abundant evidence that phytoplankton, both eukaryotic and prokaryotic, divide in phase in nature. For example, off Santa Monica Bay, California, Weiler \& Eppley (1979) found Ceratium furca to divide in synchrony. Similarly, Weiler \& Chisholm (1976) found 3 species of dinoflagellates, also from Santa Monica Bay, to be dividing in phase and could calculate their growth rates using Eq. (1). Additional field studies which indicate phased division in the sea are the pioneering research done by Swift \& Durbin (1972), and Swift et al. (1976) on Pyrocystis, as well as field observations of synchronized division of the diatom Ditylum brightwellii (Coats \& Heinbokel 1982), and other phytoplankters by Williamson (1980), Rubin (1981), Rivkin et al. (1984), Chang \& Carpenter (1985), and Waterbury et al. (1987).

The fact that cell populations may lack rhythmicity when growth rates are greater than 1 division per day (Ehret \& Wille 1970) could potentially cause problems in estimating phase durations. However, cells of some species may still travel in cohorts through the cell cycle when the population growth rate exceeds 1 division per day as implied by the studies of Edmunds \& Funch (1969), Chisholm \& Costello (1980), and Chisholm et al. (1984). Population growth rate greater than 1 division per day can be estimated if rhythmicities exist in the cell cycle.

One point should be noted in applying this method. In some phytoplankton species, the specific growth rate as a function of time has several local maxima during one light-dark cycle (Chisholm et al. 1984). This fact implies that the release factor may send out more than one cohort of cells from G0 per day. If 2 cohorts are partially overlapped, the position of the maximum of 
both cohorts may be altered. The influence of this phenomena is under our study at this moment.

If growth rate is low or moderate, our technique may also be used to estimate growth rate of prokaryotes. When the growth is slow, the prokaryotic cell cycle is similar to that of eukaryotes. However, different names are used for cell cycle phases (Chisholm et al. 1987). Prokaryotes can start a second DNA synthesis phase before entering cell division under rapid growth conditions, and this would not match the regular settings of the Takahashi-Kendall model.

The proposed method may need some modification if the target species is known to be arrested in the $G 2$ phase under certain situations. The duration of $G 2$ in such a cell cycle would not be deterministic. How this violation of the model assumption will affect the accuracy of phase duration estimates is still unclear.

Moreover, although no cell death is assumed, we think that this method will not be affected by grazing, because it is unlikely that grazers will feed selectively on cells in a particular stage of the cell cycle. As long as grazers consume cells in each compartment with the same probability, the shape of the cell cohort will be preserved as if grazing did not exist.

Finally, we believe this is a straightforward method for measuring species-specific, in situ growth rate. Incubations are not required, thus biases from bottle effects are avoided. $S$ and $G 2+M$ are by no means the only 2 phases that should be used in the growth rate estimation. Any other cell cycle segment satisfying the assumptions of our model should work as well. For example, the concept can be used when the fractions of double nucleated and newly divided cells are measured as terminal events (Weiler \& Chisholm 1976, Braunwarth \& Sommer 1985).

Acknowledgements. This research was supported by NSF grant OCE8515730 to E. J. C. We thank A. Okubo for helpful discussions about this model. Contribution 587 from the Marine Sciences Research Center.

\section{LITERATURE CITED}

Braunwarth, C., Sommer, U. (1985). Analysis of the in situ growth rates of Cryptophyceae by use of the mitotic index technique. Limnoi. Oceanogr. 30: 893-897

Carpenter, E. J., Lively, J. S. (1980). Review of estimates of algal growth using carbon-14 techniques. In: Falkowski, P. (ed.) Primary productivity in the sea. Plenum Press, New York, p. 161-178

Chang, J., Carpenter, E. J. (1985). Blooms of the dinoflagellate Gyrodinium aureolum in a Long Island estuary: box model analysis of bloom maintenance. Mar Biol. 89; 83-93

Chisholm, S. W., Armbrust, E. V., Olson, R. J. (1987). The individual cell in phytoplankton ecology: cell cycles and applications of flow cytometry. In: Platt, T., Li, W. K. W (eds.) Photosynthetic picoplankton. Can. Bull. Fish. Aquat. Sci. 214: 343-369

Chisholm, S. W., Costello, J. C. (1980). Influence of environmental factors and population composition on the timing of cell division in Thalassiosira fluviatilis (Bacillariophyceae) grown on light/dark cycles. J. Phycol. 16: 375-383

Chisholm, S. W., Vaulot, D., Olson, R. J (1984). Cell cycle controls in phytoplankton: comparative physiology and ecology. In: Edmunds, L. N., Jr. (ed.) Cell cycle clocks. Marcel Dekker, Inc., New York, p. 365-394

Coats, D. W., Heinbokel, J. F. (1982). A study of reproduction and other life cycle phenomena in planktonic protists using an acridine orange fluorescence technique. Mar Biol. 67: 71-79

Descolas-Gros, C. (1980). Use of track autoradiography in oceanography: evaluation of phytoplankton species productivity. J. Plankton Res. 2: 23-32

Douglas, D. J. (1984). Microautoradiography-based enumeration of photosynthetic phytoplankton with estimates of carbon-specific growth rates. Mar. Ecol. Prog. Ser 14: 223-228

Edmunds, L. N., Jr, Adams, K. J. (1981). Clocked cell cycle clocks. Science 211: 1002-1012

Edmunds, L. N., Jr, Funch, R. (1969). Effects of 'skeleton photoperiods and high frequency light-dark cycles on the rhythm of cell division in synchronized cultures of Euglena. Planta 87: 134-163

Eisen, M. (1979). Mathematical models in cell biology and cancer chemotherapy. Springer-Verlag, Berlin

Ehret, C. F., Wille, J. J. (1970). The photobiology of circadian rhythms in protozoa and other eukaryotic microorganisms In: Halldal. P. (ed.) Photobiology of microorganisms. John Wiley \& Sons Ltd., London, p. 369-416

Knoechel, R., Kalff, J. (1976). The application of grain density autoradiography to the quantitative determination of algal species production: a critique. Limnol. Oceanogr. 21: $583-590$

McDuff, R. E., Chisholm, S. W. (1982). The calculation of in situ growth rates of phytoplankton populations from fractions of cells undergoing mitosis: a clarification. Limnol. Oceanogr. 27: 783-788

Mitchison, J. M. (1971). The biology of cell cycle. Cambridge University Press, London

Olson, R. J., Vaulot, D., Chisholm, S. W (1986). Effects of environmental stresses on the cell cycle of two marine phytoplankton species. Plant Physiol. 80: 918-925

Owens, O. V.-H., Dresler, P., Crawford, C. C., Tyler, M. A., Seliger, H. H. (1977). Phytoplankton cages for the measurement of in situ growth rates of mixed natural populations. Chesapeake Sci. 18: 325-333

Peterson, B. (1980). Aquatic productivity and the ${ }^{14} \mathrm{C}-\mathrm{CO}_{2}$ method: a history of the productivity problem. Ann. Rev. Ecol. Syst. $11 \quad 359-385$

Rivkin, R., Seliger, H. H. (1981). Liquid scintillation counting for ${ }^{14} \mathrm{C}$ uptake of single algal cells isolated from natural samples. Limnol. Oceanogr 26: 780-785

Rivkin, R. B., Swift, E., Biggley, W H., Voytek, M. A. (1984). Growth and carbon uptake by natural populations of oceanic dinoflagellates Pyrocystis noctiluca and Pyrocystis fusiformis. Deep Sea Res. 31: 353-367

Rubin, C. G. (1981), Measurements of in situ growth rates of Gonyaulax tamarensis: the New England red tide organism. M. S. thesis, Massachusetts Institute of Technology

Sakshaug, E., Jensen, A. (1978). The use of cage cultures in studies of the biochemistry and ecology of marine phytoplankton. Oceanogr. mar. Biol. A. Rev. 16: 81-106

Smith, J. A., Martin, L. (1973). Do cells cycle? Proc. Natl. Acad. Sci. USA 70: $1263-1267$ 
Spudich, J. L., Sager, R. (1980). Regulation of the Chlamydomonas cell cycle by light and dark. J. Cell. Biol. 85: $136-145$

Swift, E., Durbin, E. G. (1972). The phased division and cytological characteristics of Pyrocystis spp. can be used to estimate doubling times of their populations in the sea. Deep Sea Res. 19: 189-198

Swift, E., Stuart, M., Meunier, V (1976). The in situ growth rates of some deep-living oceanic dinoflagellates: Pyrocystis fusiformis and Pyrocystis noctiluca. Limnol. Oceanogr. 21. $418-426$

Takahashi, M. (1966). Theoretical basis for cell cycle analysis. I. Labeled mitosis wave methods. J. theor Biol. 13: 202-211

Takahashi, M. (1968). Theoretical basis for cell cycle analysis. II. Further studies on labeled mitosis wave method. J. theor. Biol. 18: 195-209

Vaulot, D., Chisholm, S. W. (1987). A simple model of the growth of phytoplankton populations in light/dark cycles. J. Plankton Res. 9: 345-366

Venrick, E. C., Beers, J. R., Heinbokel, J. F. (1977). Possible consequences of containing microplankton for physiological rate measurements. J. exp. mar. Biol. Ecol. 26: $55-76$

Waterbury, J. B., Watson, S. W., Valois, F. W., Franks, D. G. (1987). Biological and ecological characterization of the marine unicellular cyanobacterium Synechococcus. In: Platt, T., Li., W. K. W (eds.) Photosynthetic picoplankton. Can. Bull. Fish. Aquat. Sci. 214: 343-369

Weiler, C. S., Chisholm, S. W. (1976). Phased cell division in natural populations of marine dinoflagellates from shipboard cultures. J. exp. mar. Biol. Ecol. 25: 239-247

Weiler, C. S. Eppley, R. W (1979). Temporal pattern of division in the dinoflagellate genus Ceratium and its application to the determination of growth rate. J. exp. mar. Biol. Ecol. 39: 1-24

Williamson, C. E. (1980). Phased cell division in natural and laboratory populations of marine diatoms. J. exp. mar. Biol. Ecol. 43: 271-279

Zietz, S. (1980). FP analysis. I. Theoretical outline of a new method to analyze time sequences of DNA histograms. Cell Tissue Kinet. 13: 461-471

This article was presented by Dr N. S. Fisher; it was accepted for printing on January 11, 1988 